\title{
Case Study of Enterprise Public Bidding Project Planning and Exploration
}

\author{
Xiaoli Zhao \\ Bidding Management Center of PetroChina Lanzhou Petrochemical Company, Lanzhou, Gansu \\ Province, China
}

\begin{abstract}
Keywords: public bidding; bidding planning; competitive analysis; risk prevention; technicality; economic efficiency
\end{abstract}

\begin{abstract}
This paper aims at effectively improving the success rate of bidding projects, the efficiency of bidding and the management level. Through the study of bidding planning, the initiative of each participant is mobilized, and the specialized division of labor and cooperation are carried out to form the preliminary bidding plan. The plan then would be reviewed by the decision-making level, so as to make the bidding result meet the technical and economic requirements, and realize the purpose of reducing cost and increasing efficiency. The public biding of arsenic remover for fixed bed in an enterprise in 2015 is taken as the case in this paper. The basic work is done in terms of market research, data collection of historical projects, preparation of bidding documents, and implementation of bidding. Finally, technical and commercial barriers were broken, and the arsenic removers were put into production process for one cycle ( 3 years), and the project was tracked and quantitative cost analysis was conducted.
\end{abstract}

\section{Introduction}

As an old saying goes, preparedness ensures success and unpreparedness spells failure. Without prior planning and preparation, it is difficult for any activity to achieve the expected success, and the same is true for bidding activities. Bidding planning refers to that before the launch of the bidding projects, in order to make the project successful, the enterprise shall start programming the implementation plan and ways to achieve the bidding goal according to the procurement needs and market environment. Only by making full preparations and arrangements in the early stage, implementing all the work in a predictable way, and dealing with all kinds of problems and risks that may be encountered correctly, can the public bidding project be completed with high quality and high efficiency.

Currently, the company's bidding projects are mainly subject to public bidding. If the scope of supply in the procurement requirements is vague and the technical conditions are vague, the potential tenderers' understanding of the project will be biased. Their responses to bidding documents vary greatly, which is not conducive to the comparison and selection of potential tenderers by the tenderees. Therefore, bidding planning is the basis for the improvement of the quality of public bidding and the decisive factor for the success or failure of public bidding projects. $^{[1]}$

\section{The role of biding planning}

\subsection{It is conducive to internal communication and coordination.}

Bidding and tendering activities require the cooperation of multiple departments and units within and outside the enterprise. According to the needs of public bidding projects, specific communication mechanisms and management procedures shall be formulated to reduce the possibility of conflicts of interest, buck-passing and repetitive labor. Under the overall arrangement of bidding planning, relevant departments and units shall complete various complicated tasks through cooperation according to the requirements of division of duties, quality and schedule.

\subsection{It will promote full competition among bidders.}

First of all, in the process of bidding planning, enterprises can further dig into high-quality suppliers 
to participate in the bidding. Secondly, formulating reasonable public bidding conditions and bid evaluation methods will put the competitive bidders at the same starting line, stimulating the enthusiasm of bidding. Third, actively creating bidding or strengthening the full competitive environment will encourage bidders to provide the best technical solutions and bid prices under the great competitive pressure.

\subsection{It will ensure rigorous and thorough project implementation.}

After comprehensive and careful bidding planning, the public bidding project can form a detailed implementation and operation plan. According to the division of labor and cooperation in bidding planning, it is conducive to the preparation of targeted, meticulous and rigorous technical and commercial documents by all responsible units, putting an end to low-level mistakes and omissions in bidding operation, and laying a good foundation for subsequent contract signing and contract performance.

\section{Implementation process of bidding planning}

\subsection{Determine the parties involved in bidding planning}

The parties involved in the bidding plan include the user, the purchasing management department, the technical management department and the bidding management department, which are respectively responsible for the demand analysis, business, technical and bidding support of the bidding project. For the public bidding projects with high investment risks and high sensitivity, in addition to the above parties, the enterprise's legal affairs, internal control audit and discipline inspection and supervision departments also participate in the bidding planning, which requires the enterprise's directors to directly participate in the decision-making process.

\subsection{Process of bidding planning}

\subsubsection{Data collection}

Content: current supply and demand of the market; list of potential bidders, their operation and performance, and their relationship with the history of the enterprise; the technical indicators and performance of the products purchased through bidding and the historical price of the products; results of bidding and procurement for similar projects of other enterprises.

Methods: historical bidding information, professional websites, professional institutions or expert consultation in the industry, investigation and investigation of similar projects, etc.

\subsubsection{Determining bidding objectives}

Economic objectives: to reduce purchase price and shorten purchase time as much as possible under reasonable budget constraints, and calculate the winning price range and purchase cycle range.

Technical objective: to determine the minimum and maximum technical requirements for bidding procurement, including technical specifications, performance and parameters, according to the current and future possible use requirements of the subject matter.

Social objectives: in line with national industrial policies and enterprise development strategies, in line with enterprises' social responsibilities and environmental protection obligations.

Compliance objectives: the organization and decision-making process of open bidding and procurement shall comply with relevant regulations, policies and systems of the country and enterprises. Bidding and tendering activities shall adhere to the principle of "openness, fairness, impartiality and honesty".

\subsection{Competitive analysis}

Through the analysis of the number of potential bidders in the market, the level (scale, technology and equipment, performance) and the possibility to participate in the competition, the content includes: the grade and price level of similar products in the market, the desire of potential bidders to participate in the competition, and the methods that may promote bidding competition. Through competitive analysis, relevant measures can be taken to promote competition or prevent vicious competition. 


\subsection{Preparation for bidding plan}

Before compiling the bidding plan, the project characteristics and demand information shall be analyzed, relevant documents and materials for project approval shall be consulted, and the basic information of the project shall be known. It mainly includes: project name, main functions and uses of the project, project investment nature, scale standard, technical performance, quality standard, implementation plan and other requirements and target control requirements. The main content, scope and bidding method should be in accordance with the law.

The business level of enterprise bidding and purchasing agents is different, resulting in uneven quality of bidding programs. To strengthen the preliminary preparation of the bidding project, senior experts shall be responsible for the bidding planning, and the handling personnel shall be responsible for the bidding operation. On the one hand, it can avoid the waste of scarce expert resources in specific transactional work; on the other hand, it can provide guidance for the bidding business operation of handling personnel and improve the bidding quality of enterprises as a whole.

\subsection{Preparation for bidding documents}

\subsubsection{Function of bidding documents}

The bidding documents describe in detail the technical and commercial requirements of the bidding and procurement, which are the normative documents restricting the bidding behaviors of all parties involved. The bidding documents are the extension and refinement of the bidding planning, and their contents should be consistent with the bidding planning.

\subsubsection{Preparation and management of bidding documents}

In order to ensure the quality and level of the compilation of bidding documents and prevent loopholes and errors, the compilation and management of bidding documents shall follow the principles of "technology first, business later" and "requirements first, rules later". The specific process is as follows:

First, the using unit shall compile the draft of the technical documents for bidding, and determine the basic requirements, scope of bidding and technical standards of the project subject to bidding. When the user unit has insufficient professional and technical capabilities, it may entrust the technical management department or the design unit to compile the technical documents for bidding.

Second, on the basis of the technical documents of bidding, the preparation of commercial documents of bidding, the main work is to determine the general contract terms, drafting special contract terms.

Third, according to the needs of the bidding project, the corresponding bidding document template should be selected and the bidding technical documents and business documents should be integrated to form the draft of the bidding document. In the process of the integration of the draft of the bidding document, the bidding management department shall compile the bid evaluation method, instructions to bidders, bidding document format and other professional documents.

Fourth, after the preparation of the preliminary draft of the bidding documents, the bidding administration department shall organize the users, the technical administration department and the procurement administration department to conduct a joint review of the bidding documents, which shall not be submitted to the management for examination and approval until it is approved and then released to the public.

\subsection{Risk prevention of bidding projects}

Bidding projects are faced with various risks in the implementation process, which will have a variety of adverse effects on the quality of bidding, or even lead to the failure of bidding.

When compiling the bidding documents, it is necessary to exclude possible legal risks, and the text should be standardized, logical, concise and clear, in line with the current relevant laws, regulations and policies of the country. If the tenderer requires to set the maximum price or the pre-tender bottom, it shall ask relevant professional departments to do so on the basis of in-depth and detailed understanding and prediction of the price and market conditions of the bidding materials. Strict special contractual terms should be set in the tender documents to transfer or reasonably share the 
risks that have been foreseen.

\section{Case study of public bidding plan}

Taking the public bidding and procurement of fixed bed arsenic removal agent for polypropylene plant of Lanzhou petrochemical company as the example, the bidding plan is as follows:

\subsection{Data collection}

Data collection includes historical data (including historical purchase price, quantity and total amount), market situation, supply performance of existing suppliers, and latest technology development at home and abroad, etc. In addition, the bidding project team comprehensively sorted out the technological conditions for the dearsenization agent, such as inlet content, outlet content, initial pressure drop, end pressure drop, regeneration temperature, bed regeneration times, single bed cumulative operation cycle, and catalyst activity index of the terminal product.

\subsection{Determining bidding objectives and competitive analysis}

The tenderer hopes to achieve the goal of reducing the procurement cost and optimizing the supply management of arsenic removal agent through this public bidding, and to initially form a standard bidding parameter standard.

First of all, they learned that the domestic market of arsenic removal agent technology has become mature and formed full competition. Domestic petrochemical equipment and coal chemical equipment have achieved good performance. The mature users are shown in the following table:

Table 1 Application Performance Table of Arsenic Removal Agent in Large Refining and Chemical Plant

\begin{tabular}{|c|c|c|c|c|}
\hline Num. & Users & $\begin{array}{c}\text { Num. Of } \\
\text { users }\end{array}$ & Life cycle & Plant capacity \\
\hline 1 & $\begin{array}{c}\text { Large-scale refinery and } \\
\text { coal chemical plant }\end{array}$ & 50 & $\begin{array}{c}\text { There are 4 } \\
\text { manufacturers with 4- } \\
\text { year-above life cycle }\end{array}$ & $\begin{array}{c}\text { device with a production capacity } \\
\text { of more than 70,000 tons }\end{array}$ \\
\hline 2 & $\begin{array}{c}\text { Large-scale refinery and } \\
\text { coal chemical plant }\end{array}$ & 37 & $\begin{array}{c}\text { There are 4 } \\
\text { manufacturers with 4- } \\
\text { year-above life cycle }\end{array}$ & $\begin{array}{c}\text { device with a production capacity } \\
\text { of more than 100,000 tons }\end{array}$ \\
\hline
\end{tabular}

Secondly, the usage and historical price of arsenic removal agent are analyzed. The polypropylene device has been using the arsenic removal agent produced by the import company since it was put into use in 2006, and the application effect is good. The historical price is the product price purchased in 2012 , the purchase unit price is 265,000 yuan/ton, and the purchase quantity is 32 tons.

\subsection{Bidding documents}

\subsubsection{The bid evaluation method shall be determined as "the appraised minimum bid price method" when compiling the bidding documents.}

This method can effectively promote competition and save cost. Moreover, it can prevent a few judges from discriminating against bidders or abusing their discretion on the grounds of "favoring the old customers".

4.3.2 Types and scale of bidding: AS remover; Quantity: volume: $24 M^{3}$.

4.3.3 Technical requirements:

Table 2 Technical Index Table of Arsenic Removal Agent

\begin{tabular}{|c|c|c|c|c|c|}
\hline $\begin{array}{c}\text { Index in } \\
\text { entrance }\end{array}$ & COS $\leqslant 10 \mathrm{PPM}$ & $\begin{array}{c}\text { Total sulfur } \leqslant \\
8 \mathrm{PPm}\end{array}$ & $\begin{array}{c}\text { phosphorus } \leqslant \\
0.03 \mathrm{PPM}\end{array}$ & $\begin{array}{c}\text { arsenic } \leqslant \\
2 \mathrm{PPM}\end{array}$ & $\begin{array}{c}\text { methylacetylene } \\
\leqslant 5 \mathrm{PPM}\end{array}$ \\
\hline $\begin{array}{c}\text { Index in } \\
\text { outlet }\end{array}$ & $\mathrm{COS} \leqslant 0.02 \mathrm{PPM}$ & $\begin{array}{c}\text { Total sulfur } \leqslant \\
1 \mathrm{PPm}\end{array}$ & $\begin{array}{c}\text { phosphorus } \leqslant \\
0.03 \mathrm{PPM}\end{array}$ & $\begin{array}{c}\text { arsenic } \leqslant \\
0.03 \mathrm{PPM}\end{array}$ & $\begin{array}{c}\text { methylacetylene } \\
\leqslant 3 \mathrm{PPM}\end{array}$ \\
\hline
\end{tabular}

Single bed operation cycle is more than 2 years, and double bed operation cycle is more than 4 years. Operating elasticity is $70-110 \%$ of the designed load.

The load bearing of the equipment will not be affected after the catalyst is loaded. 


\subsubsection{Performance requirements}

When preparing the performance requirements of the bidding documents, on the basis of legality and compliance, combined with the production process requirement and consideration of market research, it is demanded that the potential bidder should have more than one set of application performance in more than $70000 \mathrm{t} / \mathrm{a} 2$-ring tube process production device. The application cycle of the product shall be more than one cycle, and each cycle shall be more than three years (relevant certification materials and procurement contract shall be issued).

\subsubsection{Risk control}

First of all, because different density of arsenic removal agent will lead to different supply quantity, the volume of the reactor of the production unit is published in the bidding announcement, and the bid quantity is required to be calculated by potential bidders according to the volume of the reactor. Secondly, when both the commercial and technical terms meet the substantive requirements of the bidding documents, the candidate with the lowest bid evaluation price shall be the first winning candidate, whose supply quantity must fill the reactor. If the reactor cannot be filled, it shall be supplemented free of charge, so as to prevent bidders from winning the bid with less quantity, higher unit price and lower total price, but affecting normal operation. Instead, the production cost is increased due to speculation, and risk transfer is also realized. Finally, the payment in the bidding documents shall be subject to the management method of Lanzhou petrochemical company's fixed bed agent. The final contract quantity shall be subject to the actual loading quantity in principle, and the remaining arsenic removal agent with intact packaging shall be returned to the manufacturer in principle. $^{[2]}$

\subsection{Bidding results}

The final bidding result was RMB 3,619,200, 60.23\% lower than the estimated amount of RMB $9,100,000,57.32 \%$ lower than the transaction price of 8.48 million yuan in 2012 . The winning quantity was also reduced from 32 tons to 31.2 tons.

Through studying the bidding results, it was found that the price of imported products previously used also dropped sharply, from 265,000 yuan/ton to 185,000 yuan/ton, with a floating rate of $30.19 \% .^{[3]}$

Although the domestic agent was replaced by the imported agent through public bidding in December 2015, it needs to be tracked within the use cycle.

\subsection{Following up the application and economic analysis of arsenic removal agent in polypropylene plant}

4.5.1 Through communication and understanding with the device group, the export parameters fully meet the technical requirements after the domestic arsenic removal agent is used to participate in the process reaction.

4.5.2 Comparison of catalyst activity indexes of automotive materials, membrane materials and transparent materials of terminal products is as follows:

Table 3 Comparison of Catalyst Activity Indexes of Automotive Materials, Membrane Materials and Transparent Materials of Terminal Products

\begin{tabular}{|c|c|c|c|c|}
\hline Terminal product & $\begin{array}{c}\text { Membrane } \\
\text { material** } \\
\text { unit: kgpp/kgcat }\end{array}$ & $\begin{array}{c}\text { Automobile } \\
\text { material** } \\
\text { unit: kgpp/kgcat }\end{array}$ & $\begin{array}{c}\text { Transparent } \\
\text { material** } \\
\text { unit: kgpp/kgcat }\end{array}$ & $\begin{array}{c}\text { Single bed } \\
\text { operation } \\
\text { unit: year }\end{array}$ \\
\hline $\begin{array}{c}\text { Catalyst activity index } \\
\text { in 2012 (using } \\
\text { imported dearseners) }\end{array}$ & $27000--31000$ & $38000-40000$ & $53000-58000$ & 3 years \\
\hline $\begin{array}{c}\text { Catalyst activity index } \\
\text { in 2015 (using } \\
\text { domestic dearseners) }\end{array}$ & $27500-30500$ & $37500-40500$ & $53200-58200$ & 3 years \\
\hline
\end{tabular}

According to the data analysis, the indicators meet the product quality requirements.

4.5.3 the economic comparison between the purchase of imported dearseners and domestic dearseners is as follows: 
Table 4 The Economic Comparison between The Purchase of Imported Dearseners and Domestic Dearseners

\begin{tabular}{|c|c|c|c|c|c|c|c|c|}
\hline $\begin{array}{c}\text { Purchase } \\
\text { time }\end{array}$ & $\begin{array}{c}\text { Place of } \\
\text { production }\end{array}$ & $\begin{array}{c}\text { Purchase } \\
\text { price } \\
\text { (ten } \\
\text { thousand } \\
\text { yuan/ton) }\end{array}$ & $\begin{array}{c}\text { Purchase } \\
\text { amount } \\
\text { (ton) }\end{array}$ & $\begin{array}{c}\text { Purchase } \\
\text { sum } \\
\text { (ten } \\
\text { thousand } \\
\text { yuan) }\end{array}$ & $\begin{array}{c}\text { Operation } \\
\text { cost } \\
\text { (ten thousand } \\
\text { yuan) }\end{array}$ & $\begin{array}{c}\text { Handling } \\
\text { charges } \\
\text { (ten } \\
\text { thousand } \\
\text { yuan) }\end{array}$ & $\begin{array}{c}\text { Durable } \\
\text { year } \\
\text { (year) }\end{array}$ & $\begin{array}{c}\text { annual } \\
\text { apportion } \\
\text { ment } \\
\text { (ten } \\
\text { thousand } \\
\text { yuan) }\end{array}$ \\
\hline 2012 & U.S.A & 26.50 & 32 & 848.00 & 0 & 0 & 3 & 282.67 \\
\hline 2015 & China & 11.60 & 31.2 & 361.92 & 0 & 0 & 3 & 120.64 \\
\hline
\end{tabular}

The unloading and loading of the catalyst is done by the supplier.

From the comparison of the above table, we can see that through detailed procurement planning and public bidding, we have completed the transformation from imported agents to domestic agents, saving the purchasing capital of RMB 4.8608 million. The annual cost saving by apportionment is RMB $1,620,300 .^{[5]}$

\section{Procurement control objectives achieved through bidding planning}

5.1 Bidding planning can identify project risks in advance, adopt risk sharing and risk transfer methods, and achieve risk objective management.

5.2 Bidding planning can mobilize the enthusiasm of all project participants and achieve the goal management of project coordination.

5.3 Bidding planning can comprehensively analyze the market competitiveness of the project and control the success rate of the bidding project.

\section{Management improvement through bidding cases}

6.1 For the purchase of fixed bed agent with different densities, the volume of the reactor (or container) is published to invite bids. Potential bidders calculate the bid quantity according to the volume of the reactor and the density of the products to be bid. This method for determining the bid quantity of fixed bed agent has been popularized in rubber factories and oil refineries. ${ }^{[5]}$

6.2 In the bid for fixed bed agent project, the bidder's qualification conditions shall be set to avoid setting discriminatory conditions by taking the use cycle and production capacity of fixed bed agent into comprehensive consideration.

\section{references:}

[1] National Tender teacher professional exam resource materials know-funded committee bidding decorated professional practice [M] Beijing: China Planning Press, 2015.

[2] Rui procurement planning and examples of companies bidding analysis [J]. Bidding management, 2015 (8).

[3] Zhai Yuanxin. Management and Practice of Enterprise Tendering and Procurement [J]. China Tendering, 2014 (49): 17-18.

[4] Jiang Aihua. New Trends and Enlightenment of Tendering and Bidding Purchasing: Experiences from the Revision of International Procurement Rules [J]. Tendering and Procurement Management, 2018 (9).

[5] Liu Xu. Discussion on the Economic Effectiveness and Selection of Tender Procurement [J]. Fortune Today, 2017 (1). 